\title{
TRIGEMINAL NEURALGIA CAUSED BY ARTERIOVENOUS MALFORMATION OF THE POSTERIOR FOSSA : A CASE REPORT
}

\author{
Widodo Mardi Santoso ${ }^{1}$, Opik Jamaludin ${ }^{1}$, Catur Ari Setianto ${ }^{1}$, Neila Raisa ${ }^{1}$ \\ ${ }^{I}$ Neurology Department, Medical Faculty, Brawijaya University, Saiful Anwar General Hospital, Malang, Indonesia. \\ Correspondence : widodoneuro@gmail.com
}

\begin{abstract}
Trigeminal neuralgia (TN) is a sudden, severe, brief, stabbing, and recurrent pain within one or more branches of the trigeminal nerve. Trigeminal neuralgia has a prevalence of 0.1-0.2 per thousand and an incidence ranging from about 4-5/100,000/year up to 20/100,000/year after age 60. A 35 year old woman presented with 1 year history of right facial pain. Physical examination showed hyperalgesia and allodynia in all division of right trigeminal nerve. Magnetic resonance imaging with contrast demonstrated flow void signal in the right cerebellopontine angle. Computed tomography angiography confirmed the diagnosis of AVM (arteriovenous malformation), and demonstrated the malformed niduses were fed by the right posterior inferior cerebellar artery and the right superior cerebellar artery, and drained vein into basal vein of rosenthal, without hemorrhage or aneurysm intranidal appearance. carbamazepin $2 \times 100 \mathrm{mg}$ per oral for 7 days effectively decreased the facial pain significantly (from the numeric rating scale (NRS) score 8 to 5). Open surgical was not prefered for this patient because the AVM was small, unruptured, and located in eloquent area. Radiosurgery is considered if the medication fails. Trigeminal neuralgia with facial pain affecting all devision of nervus trigeminus with pulsatile headache can be suspected symptomatic TN. Radiological examination such as Magnetic Resonance Imaging (MRI) and Computed Tomography (CT) angiography can be performed to detect the cause of TN.
\end{abstract}

Keyword : Trigeminal neuralgia symptomatic, arteriovenous malformation, cerebellopontine angle, posterior fossa

\section{PENDAHULUAN}

Trigeminal Neuralgia (TN) adalah penyebab neuralgia yang tersering dengan insiden tahunan 4-13 / 100000 penduduk (1). Insiden meningkat seiring dengan pertambahan usia, di mana insiden tertinggi usia 60-70 tahun, jarang pada usia kurang dari 40 tahun, dengan rasio laki-laki : perempuan 1:2 $(2,3)$.

Penyebab TN sering kali tidak diketahui (idiopatik), beberapa penelitian menyatakan akibat dari: kompresi nervus trigeminus, demielinisasi, kerusakan saraf akibat traksi gigi, genetik, tumor dan multiple sclerosis, stres, imun (2). Kasus TN yang disebabkan oleh kompresi AVM adalah kasus yang jarang, dalam literatur sekitar 0,24-1,78\% dari semua kasus trigeminal neuralgia (4).

\section{KASUS}

Wanita usia 35 tahun datang ke poliklinik Saraf Rumah Sakit Saiful Anwar Malang dengan keluhan nyeri wajah sebelah kanan seperti kesetrum hingga rahang dan kepala sejak 6 bulan yang lalu. Durasi nyeri dirasakan \pm 30 detik dengan intensitas berat. Nyeri awalnya dirasakan hilang timbul, diperburuk dengan aktivitas seperti membuka mulut, makan, sikat gigi, terkena angin serta nyeri juga dirasakan saat pasien tidur. Awalnya keluhan dirasakan menghilang tanpa obat, namun dalam 2 bulan terakhir keluhan makin sering terasa dan memberat disertai nyeri kepala berdenyut area belakang kepala. Tidak didapatkan pusing berputar, jalan geloyoran ataupun gangguan pendengaran. Kejang atau mual dan mutah disangkal. Pada pemeriksaan fisik didapatkan Pada pemeriksaan fisiK didapatkan hiperalgesia dan allodinia sesuai dermatom V1,2,3 kanan. Tidak didapatkan defisit neurologis lain.

Pada pemeriksaan MRI dengan kontras didapatkan sinyal flow void di cerebellopontine angle kanan. CT angiography mengonfirmasi adanya AVM dan komponen nidus dengan feeding arteri berasal dari arteri serebelar posterior inferior dan arteri serebeli superior kanan dan draining vein ke vena basal rosenthal. Tidak tampak gambaran aneurisma intranidal maupun perdarahan.

\section{Article History:}

Received: 9 Februari 2020; Accepted: 11 Februari 2020; Published: 1 Maret 2020

Cite As:

Santoso WM, Jamaludin O, Setianto CA, Raisa N. Trigeminal neuralgia caused by arteriovenous malformation of the posterior fossa: A case report. Journal of Pain, Vertigo and Headache; 2020.1: 13-16. 
Pemberian karbamazepin 2x100 mg per oral selama 1 minggu dapat mengurangi keluhan nyeri wajah secara signifikan (dari skor NRS 8 menjadi 5). Tindakan pembedahan konvensional tidak dilakukan pada pasien ini karena AVM berukuran kecil, tidak ruptur, dan berada di area eloquen. Tindakan bedah sebagai pilihan terapi apabila terapi obat gagal.

\section{DISKUSI}

TN merupakan keluhan nyeri pada area wajah yang paling banyak ditemukan pada kasus kompresi neurovaskular karena demielinisasi serabut saraf sensoris nervus trigeminus yang disebabkan kompresi nervus trigeminus di root entry zone oleh arteri serebelar superior atau arteri serebelar anterior inferior $(1,4)$. Pada kasus ini melibatkan seluruh divisi nervus trigeminus. TN biasanya melibatkan divisi kedua atau ketiga lebih sering daripada divisi pertama, jarang bilateral, dan tidak pernah simultan pada salah satu sisi, biasanya lebih dari satu divisi yang terlibat $(1,3)$. Serangan paroksimal bertahan beberapa hari atau minggu dan menjadi lebih berat dengan nyeri konstan. Bila serangan berhenti, pasien mungkin bebas nyeri selama beberapa bulan $(1,4)$. Masih sulit membedakan gejala TN idiopatik dengan $\mathrm{TN}$ yang disebabkan AVM, terutama AVM yang tidak signifikan dan tidak tampak pada pemeriksaan angiografi, sehingga mudah sekali terjadi misdiagnosis. ${ }^{5,6}$ Menurut guideline American Academy of Neurology (AAN) dan European Federation of Neurological Societies (EFNS), diagnosis TN simptomatik dapat dibedakan dari TN klasik dengan adanya salah satu ciri berikut : defisit sensoris nervus trigeminus atau bilateral trigeminal neuralgia atau abnormalitas pada pemeriksaan elektrofisiologi refleks trigeminal (level B) (7). Pada temuan klinis nyeri kepala berdenyut di area belakang kepala dalam 2 bulan terakhir kemungkinan menunjukkan suatu gejala kompresi neurovaskular yang disebabkan oleh kompresi pembuluh darah yang berdenyut dengan kemungkinan dari feeding arteri dari AVM, arteri draining veins atau nidus malformasi. ${ }^{5}$ kejadian nyeri kepala pada AVM terjadi sekitar $7-48 \%$ kasus terutama berkaitan area oksipital dengan karakteristik menyerupai migrain atipikal, unilateral, ipsilateral lesi yang terjadi rekuren atau kronis (4).

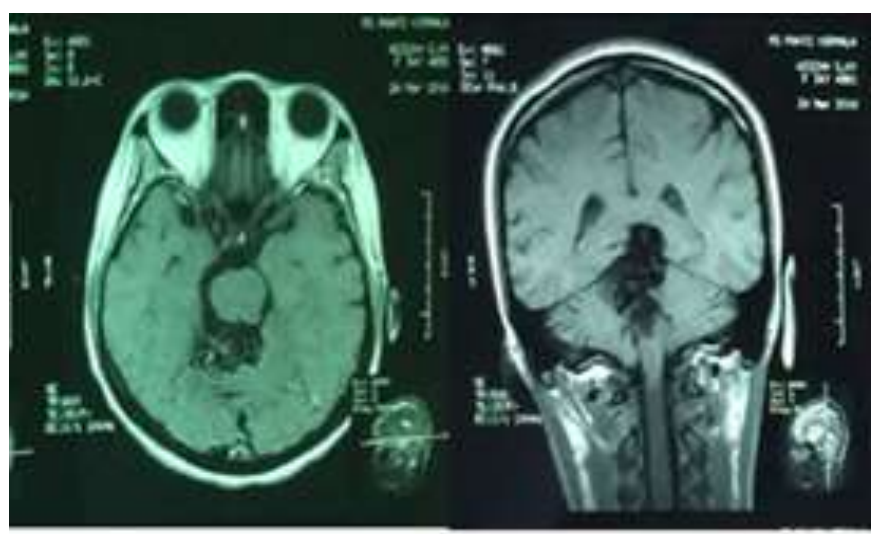

Gambar 1. Gambaran MRI kepala dengan kontras. Sinyal flow-fuid dan struktur inhomogen didaerah cerebello-pontine angle dextra dengan penambahan kontras tidak menunjukkan peningkatan signal intensity yang signifikan.
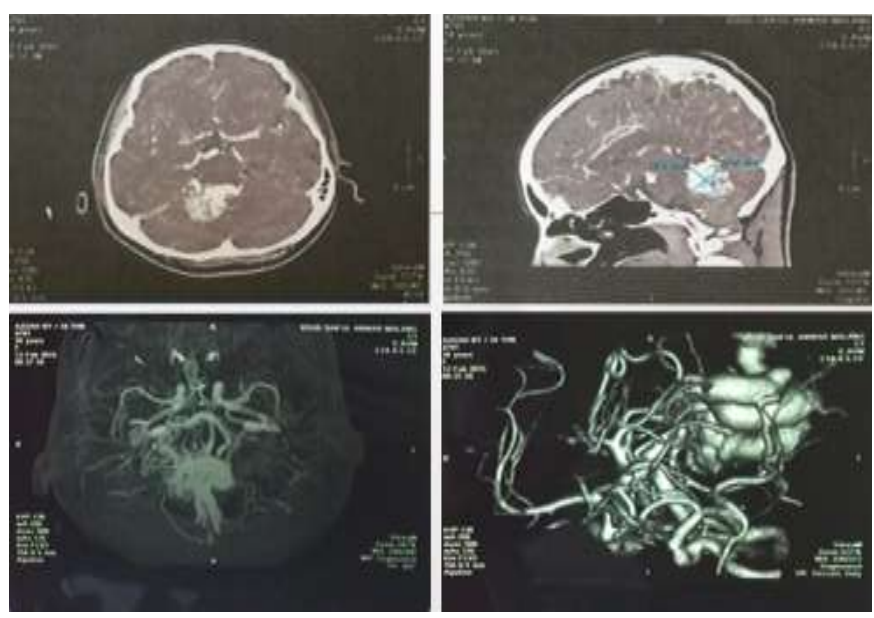

Gambar 2. Gambaran CT angiografi. Massa intraaxial tubuler turtuous, slightly homogen menyangat kuat pasca pemberian kontras dengan komponen nidus di batang otak, feeding arteri dari posterior inferior cerebelli arteri kanan dan superior cerebelli arteri kanan draining vein ke basal vein of rosenthal, diameter terbesar nidus \pm $2,6 \mathrm{~cm}$. Tidak tampak aneurisma intranidal maupun perdarahan.

Sebagian besar kasus TN terkait AVM dapat terdiagnosis dengan MRI dan angiography serebri atau selama proses operasi $(9,11)$. Pemeriksaan imaging (MRI dengan kontras, CT angiografi) sesuai gambaran AVM di batang otak (eloquent, poin 1), diameter terbesar 2,6 cm (poin 1), deep venous drainage (poin 1) sesuai Spletzer Martin Grading 3. Maka dapat disimpulkan bahwa nyeri TN yang dirasakan pasien diakibatkan oleh arterivenous malformation yang terjadi pada arteri serebelli superior yang mengompresi root entry zone nervus trigeminal di batang otak. Namun, kekurangan penggunaan sistem Spetzler-Martin untuk kasus AVM di fossa posterior adalah batasan definisi eloquen, tingkat kesulitan dalam teknik bedah, risiko perdarahan yang bervariasi dan tidak ada homogenitas dari AVM grade III $(7,8)$

Pemeriksaan digital substraction angiography (DSA) merupakan pemeriksaan baku emas untuk diagnosis TN karena ia dapat menunjukkan dengan jelas AVM, termasuk feeding arteries, niduse dan draining vein, juga menjelaskan struktur tersebut berkaitan dengan aneurisma, di mana informasi ini dapat digunakan sebagai evaluasi pasien preoperasi (3). Namun adanya penggunaan kateter invasif menjadi kendala dalam penggunaan DSA karena sangat tergantung dari kemampuan dokter yang melakukan pemasangan kateter invasif. Pemeriksaan imaging noninvasif untuk kelainan vaskular (termasuk AVM) seperti CT angiography (CTA) dan MR angiography (MRA) dinilai cukup dan baik untuk kepentingan diagnosis dan rencana penatalaksanaan AVM (9).

Dalam suatu serial kasus dengan 40 pasien yang dievaluasi, terdapat 39 pasien $(97,5 \%)$ dengan AVM di fossa posterior dan bermanifestasi TN $(9,10)$. Dalam penelitian Garcia yang mengevaluasi 375 kasus AVM, didapatkan $1,3 \%$ pasien dengan TN, 9,8 \% dari pasien AVM tersebut berada di fossa posterior dan berkembang menjadi TN. Sebagian besar pasien yang menderita TN memiliki lesi ipsilateral dengan sisi lesi, dan hanya 1 pasien dengan lesi kontralateral yang diakibatkan kompresi root entry zone nervus trigeminal kontralateral oleh arteri draining vein $(4,11)$ 
Tujuan penatalaksanaan TN idiopatik dan simptomatik adalah mengurangi nyeri. Hal ini dapat dilakukan melalui pendekatan informasi dan edukasi, terapi farmakologi, non farmakologi, dan terapi bedah. Setelah diberikan edukasi dan informasi, pada pasien ini diberikan karbamazepin 2x100 mg per oral selama 1 minggu, dan didapatkan pengurangan keluhan nyeri wajah secara signifikan (dari skor NRS 8 menjadi 5). Berdasarkan American Academy of Neurology (AAN) dan European Federation of Neurological Societies (EFNS) pilihan obat terapi anti-nyeri untuk kasus TN antara lain : Carbamazepin terbukti efektif (level A), oxcarbazepine mungkin efektif (level B), baclofen,pimozide,lamotrigin, pimozide dapat dipertimbangkan (level C) sedangkan clonazepam, gabapentin, phenitoin, tizanidin, capsaicin topikal, valproat masih kekurangan bukti untuk menentukan apakah efektif atau tidak $(8,13)$. Terapi non-farmakologi dapat dilakukan TENS, 8 sedangkan terapi bedah disarankan apabila nyeri persisten dengan semua modalitas sebelumnya. Namun tetap dengan mempertimbangkan keuntungan dan kerugian pada pasien.

Perdarahan merupakan manifestasi klinis terbanyak ditemukan pada AVM di fossa posterior di mana dalam serial kasus disebutkan insiden perdarahan subarakhnoid (75\%) dan intraparenkim (92\%). Diperkirakan kejadian perdarahan. AVM di area batang otak lebih sedikit dibandingkan dengan AVM di area serebelum. Hal ini menunjukkan bahwa adanya hubungan independen dari lokasi AVM di area infratentorial dan kejadian perdarahan (2-4). AVM fossa posterior seringkali berhubungan dengan aneurysma (25\%) pada pedikel feeding arteri pada nidus dan seringkali menyebabkan perdarahan.15 Sehingga harus menjadi perhatian serius untuk mempertimbangkan tindakan invasif pada AVM di area fossa posterior terkait tingginya morbiditas dan mortalitas pada kejadian ruptur AVM di fossa posterior. Oleh karena alasan tersebut, terapi bedah akan segera dilakukan dengan fokus evakuasi hematom karena adanya tanda-tanda efek desak ruang atau adanya hidrosefalus (7).

Pendekatan terapi bedah pada kelainan pembuluh darah merupakan opsi terapi ideal secara teori. Direkomendasikan microvascular decompression pada pasien yang tidak dapat menjalani reseksi AVM. Outcome yang baik juga dilaporkan pada embolisasi intervensi pada sebagian pasien (12). Destruksi nervus trigeminal dilaporkan memiliki angka kekambuhan yang tinggi, sehingga hanya disarankan sebagai alternatif pada pasien usia tua yang tidak bisa dilakukan operasi $(3,5)$.

Pilihan terapi bedah yang dapat dilakukan antara lain radiosurgery, open surgery, embolisasi vaskular dan kombinasi diantaranya. Umumnya pasien dengan AVM asimptomatis tidak dilakukan terapi agresif namun akan diobservasi gejala klinis secara berkala $(1,3,4)$. Radiosurgery dengan tujuan obliterasi nidus AVM diindikasikan pada AVM di area eloquen dengan morbiditas tinggi seperti area batang otak, serebelum. Embolisasi endovaskular dapat mengurangi ukuran malformasi dan aliran abnormal pembuluh darah AVM sehingga dapat mengurangi perdarahan sekunder, contoh : tindakan embolisasi pra-bedah ditujukan pada AVM kortikal ukuran besar, dan embolisasi paliatif untuk AVM ukuran besar yang tidak dapat dilakukan tindakan bedah atau radiosurgery seperti pada AVM dengan defisit neurologis progresif cepat karena tingginya aliran darah atau hipertensi vena. Sebagian besar AVM fossa posterior dapat dilakukan embolisasi endovaskular preoperatif untuk mengurangi ukuran dan dan morfologi AVM sehingga dapat mengurangi risiko perdarahan $(2,12)$.

Sebagian besar ahli bedah saraf lebih memilih radiosurgery untuk mengevaluasi secara klinis dan tidak langsung melakukan operasi pada AVM berukuran kecil (diameter <3 $\mathrm{cm}$ ), tidak ruptur, berlokasi di area eloquen atau pada pasien usia tua. Adapun AVM yang ruptur, ukuran kecil dan berada di area eloquen dan menyebabkan defisit neurologis disarankan open surgery $(3,12)$.

Dilaporkan dalam suatu serial kasus bahwa terapi inisial karbamazepin pada pasien AVM di fossa posterior dapat mengurangi nyeri secara signifikan selama 10-18 bulan. pada pasien ini untuk sementara dapat kita lanjutkan pemberian terapi per oral tersebut dengan tetap evaluasi klinis karena AVM di fossa posterior tetap memiliki risiko desak ruang dan perdarahan. Berapa lama perlunya evaluasi imaging tidak ada ketentuan khusus namun dapat disesuaikan dengan perkembangan klinis. Tindakan pembedahan konvensional tidak dilakukan pada pasien ini karena AVM berukuran kecil, tidak ruptur, dan berada di area eloquen. Namun tetap diinformasikan kemungkinan tindakan bedah sebagai pilihan terapi apabila terapi obat gagal. Dalam hal ini, kita dapat menyarankan pada pasien ini tindakan embolisasi endovaskular atau radiosurgery (5).

\section{KESIMPULAN}

Trigeminal neuralgia dengan gejala nyeri wajah pada semua divisi nervus trigeminus disertai nyeri kepala berdenyut dapat dicurigai penyebab simptomatik.

\section{DAFTAR PUSTAKA}

1. Bennetto L, Patel NK, Fuller G. Trigeminal neuralgia and its management. BMJ [Internet]. 2007 Jan 27;334(7586):201-5. Available from: https://www.ncbi.nlm.nih.gov/pubmed/17255614

2. Purdy PD, Batjer HH, Samson D. Management of hemorrhagic complications from preoperative embolization of arteriovenous malformations. $\mathbf{J}$ Neurosurg [Internet]. 1991;74(2):205-11. Available from: http://dx.doi.org/10.3171/jns.1991.74.2.0205

3. Machet A, Aggour M, Estrade L, Chays A, Pierot L. Trigeminal neuralgia related to arteriovenous malformation of the posterior fossa: Three case reports and a review of the literature. $J$ Neuroradiol [Internet]. 2012;39(1):65-70. Available from: http://dx.doi.org/10.1016/j.neurad.2011.08.001

4. García-Pastor C, López-González F, Revuelta R, Nathal E. Trigeminal neuralgia secondary to arteriovenous malformations of the posterior fossa. Surg Neurol [Internet]. 2006;66(2):207-11. Available from: http://dx.doi.org/10.1016/j.surneu.2006.01.027

5. Yuan Y, Zhang Y, Luo Q, Yu J. Trigeminal neuralgia caused by brain arteriovenous malformations: A case report and literature review. Vol. 12, Experimental and Therapeutic Medicine. Spandidos Publications; 2016. p. 69-80.

6. Işik S, Ekşi MŞ, Yilmaz B, Toktaş ZO, Akakin A, Kiliç $\mathrm{T}$. Trigeminal neuralgia caused by cerebellopontine angle 
7. arteriovenous malformation treated with Gamma knife radiosurgery. J Craniofac Surg [Internet]. 2016 Jan 1 [cited 2020 Feb 9];27(1):e55-7. Available from: http://www.ncbi.nlm.nih.gov/pubmed/26674920

8. Cruccu G, Gronseth G, Alksne J, Argoff C, Brainin M, Burchiel $\mathrm{K}$, et al. AAN-EFNS guidelines on trigeminal neuralgia management. Eur $\mathrm{J}$ Neurol [Internet]. 2008;15(10):1013-28. Available from: http://dx.doi.org/10.1111/j.1468-1331.2008.02185.x

9. Devor M, Amir R, Rappaport ZH. Pathophysiology of Trigeminal Neuralgia: The Ignition Hypothesis. Clin J Pain [Internet]. 2002;18(1):4-13. Available from: http://dx.doi.org/10.1097/00002508-200201000-00002

10. Shankar JJS, Lum C, Chakraborty S, Dos Santos M. Cerebral vascular malformations: Time-resolved CT angiography compared to DSA. Neuroradiol J [Internet]. 2015 Jun;28(3):310-5. Available from: https://www.ncbi.nlm.nih.gov/pubmed/26246101

11. Sumioka S, kondo A, tanabe H, Yasuda S. Intrinsic Arteriovenous Malformation Embedded in the Trigeminal Nerve of a Patient With Trigeminal Neuralgia. Neurol Med Chir (Tokyo) [Internet]. 2011;51(9):639-41. Available from: http://dx.doi.org/10.2176/nmc.51.639

12. Sato K, Jokura H, Shirane R, Akabane T, Karibe H, Yoshimoto T. Trigeminal neuralgia associated with contralateral cerebellar arteriovenous malformation. J Neurosurg [Internet]. 2003;98(6):1318. Available from: http://dx.doi.org/10.3171/jns.2003.98.6.1318 